\title{
Research on Semiactive Control of Civil Engineering Structure Based on Neural Network
}

\author{
Longji Jian $\mathbb{D}^{1,2}$ Feifei Song, ${ }^{2}$ and Yuansong Huang ${ }^{2}$ \\ ${ }^{1}$ College of Civil Architecture and Environment, Xihua University, Chengdu 610039, China \\ ${ }^{2}$ Sichuan Qinghe Science and Technology Co., Ltd., Chengdu 610039, China \\ Correspondence should be addressed to Longji Jian; biounicom@mail.xhu.edu.cn
}

Received 8 July 2020; Revised 30 July 2020; Accepted 23 August 2020; Published 22 September 2020

Academic Editor: Hongju Cheng

Copyright (c) 2020 Longji Jian et al. This is an open access article distributed under the Creative Commons Attribution License, which permits unrestricted use, distribution, and reproduction in any medium, provided the original work is properly cited.

\begin{abstract}
In order to improve the strength of civil engineering structure, a semiactive control model of civil engineering structure based on neural network is proposed, and the control constraint parameter model of semiactive regulation of civil engineering structure is constructed. Combined with the controlled object model, the semiactive control model of civil engineering structure is designed, the mechanical analysis model of civil engineering structure is established, and the semiactive regulation of civil engineering structure is carried out by the small disturbance suppression method. The semiactive adjustment of civil engineering structure is carried out by using the structural strength fusion tracking method. Taking the internal strength and shock yield response of civil engineering structure as constraint parameters, the semiactive control of civil engineering structure is carried out and PID neural network is used to optimize the control system. The simulation results show that the semiactive control of civil engineering structure with this method has good stability, and the strength and yield response strength of civil engineering structure are improved, and it has good control efficiency.
\end{abstract}

\section{Introduction}

With the development of civil engineering, people pay more attention to the research of civil engineering construction. The strength of civil engineering structure is an important measure to the surface of civil engineering. Under the condition of high load, the stress of external prestress of civil engineering structure is analyzed, and the average strain coordinated support is decomposed under a multifreedom structure [1]. Under different stress loads and damping loads, the stress intensity of civil engineering structures can be improved and semiactive control of civil engineering structures can be realized by means of experimental loading and mathematical simulation of external prestressing forces of civil engineering structures. The study of semiactive control method of civil engineering structure has great value in improving the structural strength of civil engineering [2].

At present, most scholars at home and abroad use the moment-curvature method to analyze the external prestressing force of civil engineering structures [3] and calculate the external shear capacity of civil engineering structures by using the nodal compression bar model. The bond stress of civil engineering structure is increased, the cracking point of civil engineering structure is reduced effectively, and the effect of yield point on steel yield is reduced. However, in the process of structural stress transplantation, the constraint reinforcement method is adopted in this method [4]. It is easy to produce the prestress transfer with active lateral restraint, which leads to an inaccurate analysis of the stress situation of civil engineering structure. The improved design is carried out; in reference [5], an analysis model of external prestressing force of high load civil engineering structure based on prestressed fiberboard reinforcement is proposed. In the local coordinate system of element, the linear load loading of high load civil engineering structure is carried out, and the yield effect of load loading on the external prestressing force of civil engineering structure and the compression of vertical shear force are analyzed. The stress intensity and service life of civil engineering structures are improved, but the method is easy to cause the expansion and deformation of civil engineering structures in the course of load loading, and there are errors in the analysis of 
prestressing forces under the action of disturbed stress field. In addition, in reference [6], a stress analysis model of external prestressing of high load civil engineering structures based on coordinated control of average strain is proposed. The total shear deformation of joints is used to decompose the external core beams of high load civil engineering structures. The characteristic reconstruction and stress characteristic decomposition are carried out on the confined parameters in the direction of the column, the load-loading test is carried out in the average strain circle, and the constitutive relation between the external prestress and the shear stress of the steel bar in the high-load civil engineering structure is obtained. The stress analysis is realized, but the calculation cost of the above analysis model is large and the process of realization is complex, which is not good for the semiactive control efficiency of civil engineering structure [7-9].

Aiming at the above problems, a semiactive control model of civil engineering structure based on neural network is proposed in this paper, and the control constraint parameter model of semiactive regulation of civil engineering structure is constructed. Combined with the controlled object model, the semiactive control model of civil engineering structure is designed, the mechanical analysis model of civil engineering structure is established, and the semiactive regulation of civil engineering structure is carried out by a small disturbance suppression method. The semiactive adjustment of civil engineering structure is carried out by using the structural strength fusion tracking method. Taking the internal strength and shock yield response of civil engineering structure as constraint parameters, the semiactive control of civil engineering structure is carried out and PID neural network is used to optimize the control system. Finally, the performance test is carried out through the simulation experiment, which shows the superiority of this method in improving the semiactive control ability of civil engineering structure.

\section{The Proposed Model}

Firstly, the constitutive relation model of external prestressing joint of high-load civil engineering structure is constructed, the structural mechanics analysis is carried out, and the structure of civil engineering is designed with a concrete columnar structure [10].

The neural network consists of multilayer neural networks. Different network layers are composed of multiple 2D planes. Each plane is composed of multiple independent neurons. The network structure is shown in Figure 1 .

The network structure is a civil engineering structural unit with an input value of $32 \times 32$. After processing at the network layer, a $6 \times 28 \times 28$ three-dimensional matrix is obtained. This matrix is called a feature plane and can be obtained by processing characteristic parameters of $6 \times 14$. The feature plane of 14 uses the network layer to extract features from the visual image, and the pooling layer performs parameter reduction processing on the parameters, combines the two to form multiple convolution groups, extracts fea-

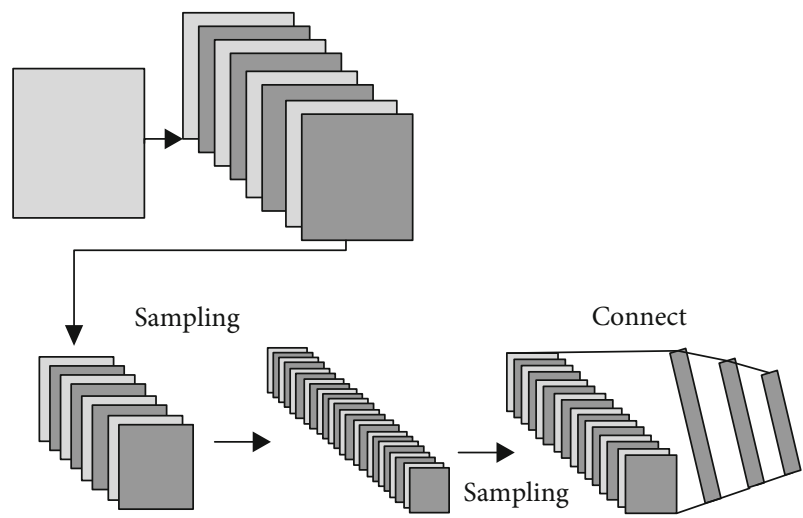

FIGURE 1: Schematic diagram of neural network structure.

tures layer by layer, and implements the neural network under several connection layers.

The mechanical properties of concrete columns with steel strip spacing distribution in the element local coordinate system are investigated. The three-channel model of civil engineering structural mechanics can be expressed as follows:

$\left\{\begin{array}{l}\ddot{\varphi}_{a}=-\left(b_{1}+\Delta b_{1}\right) \dot{\varphi}_{a}-\left(b_{2}+\Delta b_{2}\right) \varphi_{a}-\left(b_{3}+\Delta b_{3}\right) \delta_{\varphi}+f d_{1}, \\ \ddot{\psi}_{a}=-\left(b_{1}+\Delta b_{1}\right) \dot{\psi}_{a}-\left(b_{2}+\Delta b_{2}\right) \psi_{a}-\left(b_{3}+\Delta b_{3}\right) \delta_{\psi}+f d_{2}, \\ \ddot{\gamma}=-\left(d_{3}+\Delta d_{3}\right) \delta_{\gamma}+f d_{3} .\end{array}\right.$

The shear strain and control torque of civil engineering structures are calculated. By analyzing the constitutive relation of the core region of the node, we can get further results:

$$
\left\{\begin{array}{l}
\ddot{\varphi}_{a}=-b_{1} \dot{\varphi}_{a}-b_{2} \varphi_{a}-b_{3} \delta_{\varphi}+\rho_{1} \\
\ddot{\psi}_{a}=-b_{1} \dot{\psi}_{a}-b_{2} \psi_{a}-b_{3} \delta_{\psi}+\rho_{2} \\
\ddot{\gamma}=-d_{3} \delta_{\gamma}+\rho_{3}
\end{array}\right.
$$

In which, $\rho_{1}=-\Delta b_{1} \dot{\varphi}_{a}-\Delta b_{2} \varphi_{a}-\Delta b_{3} \delta_{\varphi}+f d_{1}, \quad \rho_{2}=$ $-\Delta b_{1} \dot{\psi}_{a}-\Delta b_{2} \psi_{a}-\Delta b_{3} \delta_{\psi}+f d_{2}$, and $\rho_{3}=-\Delta d_{3} \delta_{\gamma}+f d_{3}$ are uncertain items.

Under the same specimen, the mechanical analysis model of civil engineering structure is established, and the semiactive regulation of civil engineering structure is carried out by using a small disturbance suppression method [11]. The load model of civil engineering structure is described as follows:

$$
\ddot{\varphi}_{a}=a_{1} \dot{\varphi}_{a}+a_{2} \varphi_{a}+b u+f_{d} .
$$

In which, $b>0$ is the unit load, $\dot{\varphi}_{a}$ is the internal structural mechanical distribution, $u$ is the load characteristic input, and $f_{d}$ is the external characteristic quantity.

According to the basic connotation of the approximate detection expected value to perceive the correlation between the stress of the civil engineering structure and to accurately monitor the stress transmission process of the multichannel 


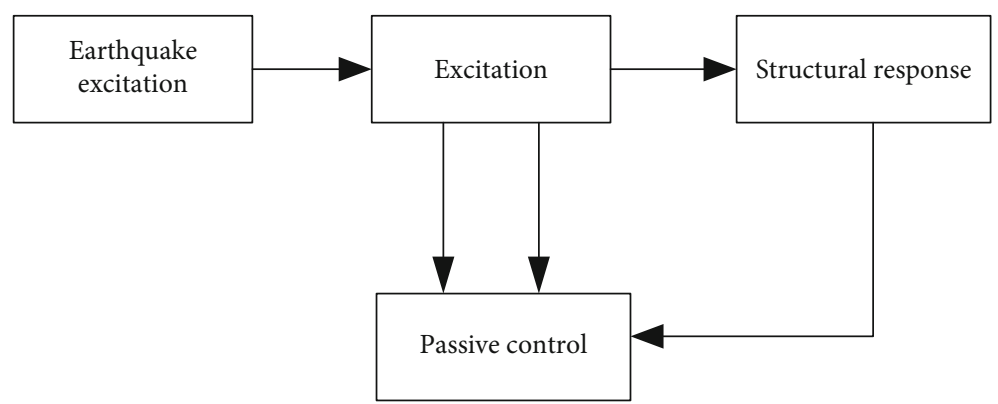

Figure 2: Passive control schematic diagram.

civil engineering structure with the minimum cost, the set of multichannel encrypted transmission civil engineering stress at time $t$ can be expressed as:

$$
S_{t}=\left\{a_{1}(t), a_{1}(t), \cdots \cdots, a_{n}(t)\right\} .
$$

The basic ranking method for sensing stress of civil structures in a set can be defined as $\gamma\left(x_{i}, S_{t}\right)$ :

$$
\gamma\left(x_{i}, S_{t}\right):\left|\left\{i \mid a_{i}(t) \geq x_{i}\right\}\right| \text {. }
$$

Then, the monitoring results obtained based on the algorithm can be expressed asTop $\left(n, S_{t}\right)$, which meet the following conditions:

$$
\left\{\begin{array}{l}
\operatorname{Top}\left(n_{i}, S_{t}\right) \subset S_{i}, \\
\left|\operatorname{Top}\left(n_{i}, S_{t}\right)\right|=n, \\
\forall x \in \operatorname{Top}\left(n_{i}, S_{t}\right), \forall y \in S_{i}, x>y .
\end{array}\right.
$$

If the perceptual range of the cluster head node is not beyond the maximum of the filter, then in order to save the energy consumption of the node, it is not necessary to send the perceptual information to the common node to obtain the lowest load characteristic quantity.

The stress distribution method of the civil engineering structure is used to carry out the finite element analysis, and the load characteristic quantity of the civil engineering structure is obtained as follows:

$$
b^{-1} \ddot{\varphi}_{a}-b^{-1}\left(a_{1} \dot{\varphi}_{a}+a_{2} \varphi_{a}\right)=u+b^{-1} f_{d}+\operatorname{Top}\left(n_{i}, S_{t}\right)
$$

Set $M=b^{-1}, h\left(\varphi_{a}, \dot{\varphi}_{a}\right)=-b^{-1}\left(a_{1} \dot{\varphi}_{a}+a_{2} \varphi_{a}\right)$, and $d(t)=$ $b^{-1} f_{d}$, the yield response strength of civil engineering structure is as follows:

$$
M \ddot{\varphi}_{a}+h\left(\varphi_{a}, \dot{\varphi}_{a}\right)=u(t)+d(t)
$$

The semiactive control constraint parameters of civil engineering structures consist of two parts: $M$ and $h\left(\varphi_{a}, \dot{\varphi}_{a}\right)$, which are determined and uncertain:

$$
\begin{gathered}
M=M_{n}+\Delta M, \\
h\left(\varphi_{a}, \dot{\varphi}_{a}\right)=h_{n}\left(\varphi_{a}, \dot{\varphi}_{a}\right)+\Delta h\left(\varphi_{a}, \dot{\varphi}_{a}\right) .
\end{gathered}
$$

In which, $M_{n}$ and $h_{n}\left(\varphi_{a}, \dot{\varphi}_{a}\right)$ are semiactive control determinants for civil engineering structures and $\Delta M$ and $\Delta h\left(\varphi_{a}, \dot{\varphi}_{a}\right)$ are semiactive control uncertainties for civil engineering structures [12].

The $\mathrm{k}-\varepsilon$ two-equation turbulence model is constructed [13], and it can be further obtained:

$$
M_{n} \ddot{\varphi}_{a}+h_{n}\left(\varphi_{a}, \dot{\varphi}_{a}\right)=u(t)+\rho(t)
$$

where

$$
\rho(t)=-\Delta M \ddot{\varphi}_{a}-\Delta h\left(\varphi_{a}, \dot{\varphi}_{a}\right)+d(t)
$$

Assume that the upper bound of uncertainty of semiactive control system of civil engineering structure is $\bar{\rho}(t)$, that is,

$$
|\rho(t)|<\bar{\rho}(t)
$$

The constraint parameter model of semiactive control of civil engineering structure is constructed, and the control law is optimized by combining the stress characteristic distribution.

Passive control does not rely on external energy input. It is the installation of specific parameters of the antivibration antiseismic device in the designated parts of the building structure, such as energy dissipation, vibration isolation, and vibration absorption techniques, in order to prevent the ground motion from harming the building structure. The passive control block diagram is shown in Figure 2.

Passive control is divided into energy dissipation, base isolation, and tuned damping. Energy dissipation and shock absorption are to set the damper at the node or joint of the building structure, or to design the support of the building structure or the shear wall as energy-consuming components. When the earthquake is relatively small, the energy dissipation damper is in a state of elasticity. When a strong earthquake occurs, energy-consuming devices first consume a large amount of energy entering the structure into an inelastic state, thereby preventing the building structure from entering an inelastic state and protecting the building structure from damage. Base isolation means that the isolation control device is installed on the base of the building structure so as to isolate the seismic energy and transfer it to the upper part of the building, thus avoiding the destruction of the building structure caused by the earthquake. Tuning 


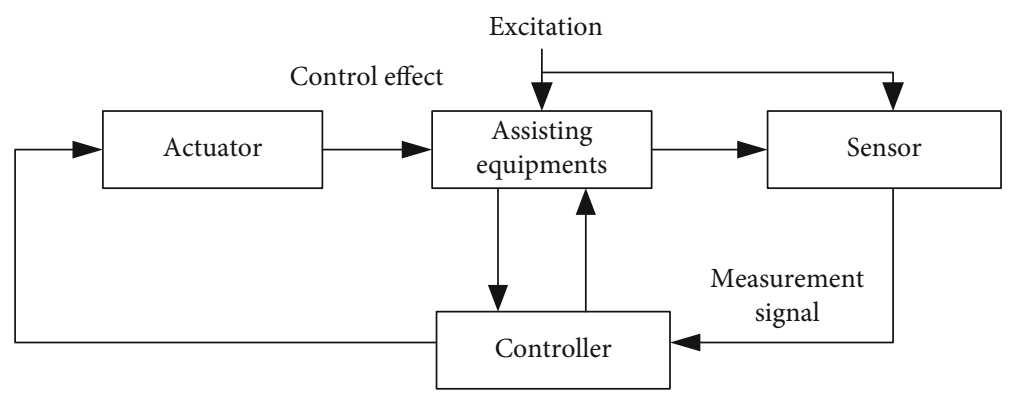

FIgURe 3: Active control schematic diagram.

vibration reduction is to reduce the vibration of the earthquake to the building structure by adding additional substructures to shift the vibration of the earthquake to the building structure.

Active control relies on external energy. During the vibration of the building structure in the event of an earthquake, active control devices generate control forces acting on the building structure, thereby rapidly reducing the vibration effect of the earthquake on the building structure. Active control principle is shown in Figure 3. It can be seen from the figure that the active control system consists of three parts: controller, sensor, and actuator. The working principle is as follows: when an earthquake occurs, the sensor transmits the detected seismic excitation or the vibration response of the building structure to the controller. According to the received information, the controller calculates the control force according to a certain control algorithm and issues a control command to the controller, and the actuator receives the control instruction to generate a control function that controls the force acting on the building structure, thereby reducing the damage of the earthquake to the building structure. The control force generated by the active control is changed in real-time with the different seismic waves, and the control effect is basically not affected by the characteristics of the seismic wave and is more advantageous than the passive control.

The active control overcomes the dependence of the passive control on the intensity and spectral characteristics of the seismic wave and is basically independent of this, so the active control can perform real-time control and can meet the high-precision control requirements, with good shock absorption effect and adaptability. However, the active control of the control device is entirely dependent on the external high-power energy to drive; when the earthquake occurs, the power is not guaranteed and the reliability of the active control system will be greatly reduced, so its stability is poor. Moreover, the active control system has a complicated structure and a relatively high cost, and it is difficult to apply it. In addition, active control systems need to perform signal processing, control algorithm implementation, and drive device actions during the operation. These require some time, which may cause time lag. Therefore, there is no large-scale application of active control systems in today's building structures.

The semiactive control of the civil engineering structure is developed from the vibration control of the active structure. The principle block diagram is shown in Figure 4. The control process of semiactive control relies on the vibration response and seismic excitation of the building structure, and it can change the stiffness or damping parameter of the semiactive control device in real-time with little external energy, thereby reducing the vibration response of the building structure, and can realize realtime and adjustable control of building structure. Semiactive control is a kind of parameter control. According to the vibration response, the parameters of the actuator can be directly adjusted to achieve a good shock absorption effect. It can be said that so far, in the structural vibration control method, semiactive control has the most prospects for civil engineering applications and the highest performance-cost ratio.

The commonly used control devices in semiactive control are variable damping and variable stiffness types:

(1) Variable damping semiactive control system. Variable damping semiactive control system is to install the variable damping device in the appropriate part of the building structure, according to the structure of the building. The vibration response adjusts the parameters of the variable damping device in realtime to provide a corresponding damping force, which reduces the vibration response of the building structure. In 1997, for the first time in the United States, active variable damping control devices were used on steel bridges to reduce the vibration generated by large vehicles, and the control effect was significant. Domestic Li Hui and others also conducted research to study the active variable damping control device for civil engineering.

(2) Variable stiffness semiactive control system. The variable stiffness semiactive control system is based on the stiffness of the building structure between the layers to adjust the stiffness of the building structure in real-time according to the seismic response. This changes the dynamic characteristics of the building structure, thereby reducing the damage of the earthquake to the building structure. KoboriT et al., after systematically researching and experimentally studying the variable stiffness control system, installed the active variable stiffness control device on a practical three-story building in Tokyo. This was the first case 


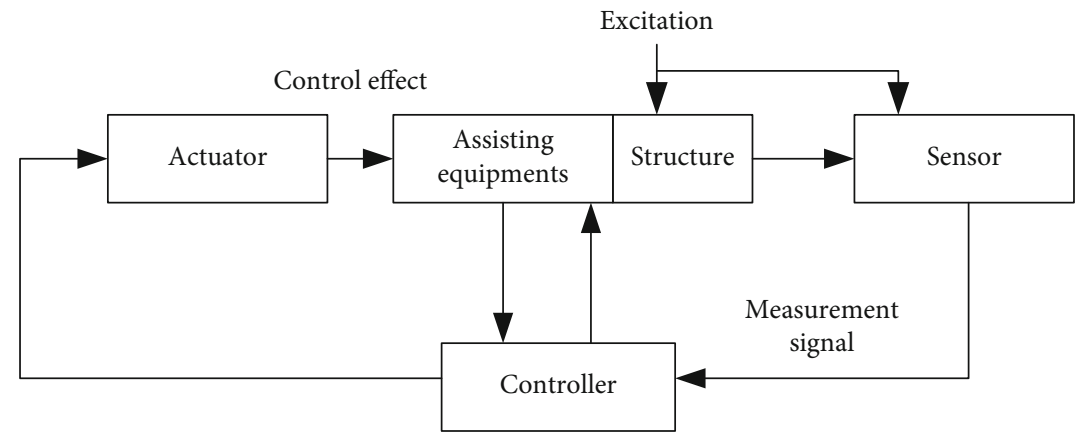

FIgURE 4: Semiactive control schematic diagram.

in the world and was carried out. Earthquake observation and test and the control effect are very good.

The semiactive control device has a simple structure and can be adjusted by itself. The required energy is much less than that of the active structure, and a greater control force can be obtained. In addition, the semiactive control has a damping effect that is close to that of the active control, and the stability is better because the control force generated by the semiactive control device is always opposite to that of the building structure. The more prominent advantage of semiactive control is that when the earthquake occurs, the power supply is interrupted and can be used as a passive damping device.

Combined with the controlled object model, the semiactive control model of civil engineering structure is designed, and the interface curvature response method is applied to carry out dynamic curvature correction:

$$
\left\{\begin{array}{l}
e_{1}=\varphi_{a}-\varphi_{a d} \\
e_{2}=\dot{\varphi}_{a}-\dot{\varphi}_{a d}
\end{array}\right.
$$

When the uncertainty of the system is not considered [14], the transverse elastic modulus distribution of the bearing capacity of civil engineering structures is obtained:

$$
\left\{\begin{array}{l}
\dot{e}_{1}=e_{2}, \\
\dot{e}_{2}=M_{n}^{-1} u-M_{n}^{-1} h_{n}\left(\varphi_{a}, \dot{\varphi}_{a}\right)-\ddot{\varphi}_{a d} .
\end{array}\right.
$$

The sliding surface of semiactive control of civil engineering structure is defined as:

$$
s=c e_{1}+e_{2} .
$$

Then,

$$
\dot{s}=\dot{c} \dot{e}_{1}+\dot{e}_{2}=c \dot{e}_{2}+\dot{e}_{2} .
$$

The bearing capacity attenuation term is:

$$
\dot{s}=0 .
$$

The control characteristic function of civil engineering structure is:

$$
\begin{aligned}
c e_{2}+\dot{e}_{2} & =c e_{2}+\ddot{\varphi}_{a}-\ddot{\varphi}_{a d} \\
& =c e_{2}+M_{n}^{-1} u-M_{n}^{-1} h_{n}\left(\varphi_{a}, \dot{\varphi}_{a}\right)-\ddot{\varphi}_{a d}=0 .
\end{aligned}
$$

The equivalent control law is obtained as:

$$
u_{e q}=h_{n}\left(\varphi_{a}, \dot{\varphi}_{a}\right)+M_{n} \ddot{\varphi}_{a d}-M_{n} c e_{2} .
$$

Considering the uncertainty of the system, the distribution law of structural mechanics is chosen as:

$$
u_{0}=-\operatorname{sgn}\left(M_{n}\right) \bar{\rho}(t) \operatorname{sgn}(s) .
$$

Considering the influence of deterioration velocity parameters, the total joint stress of multiple connection members is obtained:

$$
\begin{aligned}
u & =u_{e q}+u_{0} \\
& =h_{n}\left(\varphi_{a}, \dot{\varphi}_{a}\right)+M_{n} \ddot{\varphi}_{a d}-M_{n} c e_{2}-\operatorname{sgn}\left(M_{n}\right) \bar{\rho}(t) \operatorname{sgn}(s) .
\end{aligned}
$$

The control cash model of civil engineering structural mechanics is constructed. Under the limit tension strain condition of FRC, the compression strength reduction coefficient is introduced and the fuzzy PID neural network is used to optimize the control law [15].

\section{Semiactive Control Optimization of Civil Engineering Structures}

In this paper, a semiactive control model of civil engineering structure based on neural network is proposed [16]. The semiactive control of civil engineering structure is carried out with the internal strength and shock yield response of civil engineering structure as constraint parameter, and PID is adopted. Neural network is used to optimize the control system. The semiactive regulation of civil engineering 
structures is carried out by using the method of small disturbance suppression. The Lyapunov function is defined as [17]:

$$
V=\frac{1}{2} s^{2}
$$

Then,

$$
\begin{aligned}
\dot{V}= & s \dot{s}=s\left[c e_{2}+M_{n}^{-1} u-M_{n}^{-1} h_{n}\left(\varphi_{a}, \dot{\varphi}_{a}\right)-\ddot{\varphi}_{a d}+M_{n}^{-1} \rho(t)\right] \\
= & s c e_{2}+s M_{n}^{-1}\left(h_{n}\left(\varphi_{a}, \dot{\varphi}_{a}\right)+M_{n} \ddot{\varphi}_{a d}-M_{n} c e_{2}\right. \\
& \left.-\operatorname{sgn}\left(M_{n}\right) \bar{\rho}(t) \operatorname{sgn}(s)\right)-s M_{n}^{-1} h_{n}\left(\varphi_{a}, \dot{\varphi}_{a}\right)-s \ddot{\varphi}_{a d}+s M_{n}^{-1} \rho(t) \\
= & s M_{n}^{-1} \rho(t)-s M_{n}^{-1} \operatorname{sgn}\left(M_{n}\right) \bar{\rho}(t) \operatorname{sgn}(s) \\
= & s M_{n}^{-1} \rho(t)-\left|s M_{n}^{-1}\right| \bar{\rho}(t) \leq\left|s M_{n}^{-1}\right||\rho(t)|-\left|s M_{n}^{-1}\right| \bar{\rho}(t) \\
= & \left|s M_{n}^{-1}\right|(|\rho(t)|-\bar{\rho}(t))<0 .
\end{aligned}
$$

SPIDNN is selected as a learning network for semiactive control of civil engineering structure. It is a threelayer forward neural network, which is called $2 \times 3 \times 1$ structure. There are two neurons in the input layer of SPIDNN and two neural networks for semiactive control of civil engineering structure. The output of the branch $x_{1}, x_{2}, \ldots, x_{n}$ is multiplied by the sum of the weight value $w_{1 j}, w_{2 j}, \ldots, w_{n j}$, respectively, that is, the stress distribution of semiactive control of civil engineering structure is expressed as follows [18]:

$$
\text { net }_{j}=\sum_{i=1}^{n} w_{i j} x_{i}(t), \quad i \neq j .
$$

Using the neuron state $u_{j}$ as the independent variable, the output value of the neuron can be generated according to the semiactive control output function of the civil engineering structure, namely:

$$
x_{j}(k)=f\left(u_{j}(t)\right)
$$

The Sigmoid function is used to adjust the semiactive control of civil engineering structure $[19,20]$. Its expression is:

$$
f(x)=\frac{1}{1+e^{-x}}
$$

There are two neurons in the input layer of SPIDNN neural network with semiactive control of civil engineering structure. At any sampling time, the input layer of SPIDNN neural network is the input of the SPIDNN neural network:

$$
\operatorname{net}_{i}(k)=r_{i}(k), \quad i=1,2
$$

In which, the weight $\omega_{i j}(i=1,2 ; j=1,2,3)$ of the input layer to the hidden layer is fixed, and the yield response strength of the semiactive control of the civil engineering structure is as follows $[21,22]$ :

$$
\widehat{\bar{\rho}}(x, \omega)=\omega_{1}^{\prime} \sigma_{1}\left(\varphi_{a}, \dot{\varphi}_{a}\right)+\omega_{2}^{\prime} \sigma_{2}\left(\varphi_{a}, \dot{\varphi}_{a}\right)+\omega_{3}^{\prime} \sigma_{3}\left(\varphi_{a}, \dot{\varphi}_{a}\right),
$$

In which, $\sigma_{j}\left(\varphi_{a}, \dot{\varphi}_{a}\right)$ is the output of the hidden layer of semiactive control neural network for civil engineering structures; it is expressed as:

$$
\left\{\begin{array}{l}
\sigma_{1}\left(\varphi_{a}, \dot{\varphi}_{a}\right)=\frac{1}{1+e^{-\left(\omega_{11} \varphi_{a}+\omega_{21} \dot{\varphi}_{a}\right)},} \\
\sigma_{2}\left(\varphi_{a}, \dot{\varphi}_{a}\right)=\frac{1}{1+e^{-\int\left(\omega_{21} \varphi_{a}+\omega_{22} \dot{\varphi}_{a}\right) d t}}, \\
\sigma_{3}\left(\varphi_{a}, \dot{\varphi}_{a}\right)=\frac{1}{1+e^{-d\left(\omega_{11} \varphi_{a}+\omega_{21} \dot{\varphi}_{a}\right)}} .
\end{array}\right.
$$

Taking the internal strength and shock yield response of civil engineering structure as constraint parameters, semiactive control of civil engineering structure is carried out, and the variable structure control law of semiactive control of civil engineering structure is obtained [23]:

$$
u=h_{n}\left(\varphi_{a}, \dot{\varphi}_{a}\right)+M_{n} \ddot{\varphi}_{a d}-M_{n} c e_{2}-\operatorname{sgn}\left(M_{n}\right) \widehat{\bar{\rho}}(t) \operatorname{sgn}(s) .
$$

The elastic model distribution model of civil engineering structural components is established under different loadbearing models, and the upper bound of uncertain parameters satisfies the requirements [24]:

$$
\bar{\rho}(t)-|\rho(t)|>\varepsilon_{0}>\varepsilon_{1} .
$$

Note $\boldsymbol{\omega}^{*}=\left[\begin{array}{lll}\omega_{1}^{*} & \omega_{2}^{*} & \omega_{3}^{*}\end{array}\right]$.

Adaptive algorithm is used to adjust weights online:

$$
\begin{gathered}
\widehat{\boldsymbol{\omega}}=\eta\left|s M_{n}^{-1}\right| \boldsymbol{\sigma}\left(\varphi_{a}, \dot{\varphi}_{a}\right), \\
\eta=\left|M_{n}^{-1}\right|\left(\varepsilon_{0}-\varepsilon_{1}\right)>0 .
\end{gathered}
$$

The Lyapunov function of semiactive control for civil engineering structures is defined as:

$$
V=\frac{1}{2} s^{2}+\frac{1}{2} \eta^{-1} \tilde{\boldsymbol{\omega}}^{\mathrm{T}} \tilde{\boldsymbol{\omega}}
$$




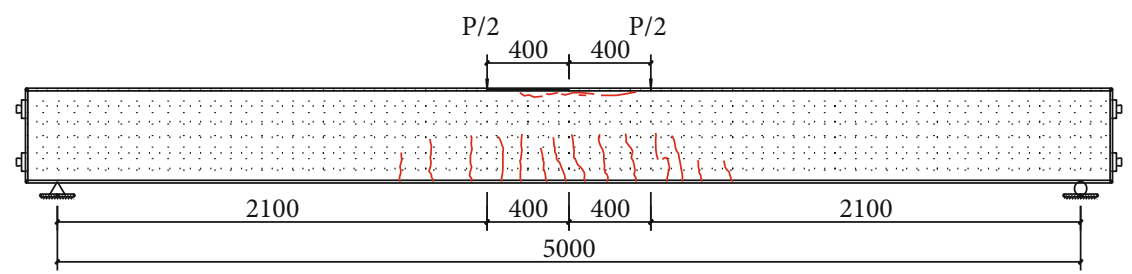

(a) RCCb1

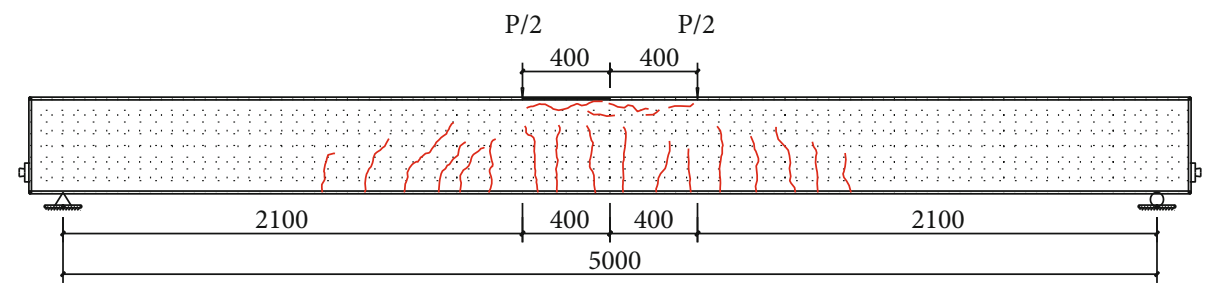

(b) RCCb2

FIgURE 5: Structural mechanics analysis of civil engineering.

In which, $\tilde{\boldsymbol{\omega}}=\boldsymbol{\omega}^{*}-\widehat{\boldsymbol{\omega}}$. Then:

$$
\begin{aligned}
& \dot{V}=\dot{s} \dot{\boldsymbol{s}}-\eta^{-1} \tilde{\boldsymbol{\omega}}^{T} \dot{\widehat{\boldsymbol{\omega}}} \\
& =s\left(c e_{2}+M_{n}^{-1} u-M_{n}^{-1} h_{n}\left(\varphi_{a}, \dot{\varphi}_{a}\right)-\ddot{\varphi}_{a d}\right. \\
& \left.+M_{n}^{-1} \rho(t)\right)-\eta^{-1} \tilde{\boldsymbol{\omega}}^{\mathrm{T}} \dot{\hat{\boldsymbol{\omega}}} \\
& =s c e_{2}-s M_{n}^{-1} h_{n}\left(\varphi_{a}, \dot{\varphi}_{a}\right)-s \ddot{\varphi}_{a d}+s M_{n}^{-1} \rho(t) \\
& -\eta^{-1} \tilde{\boldsymbol{\omega}}^{\mathrm{T}} \dot{\hat{\boldsymbol{\omega}}}+s M_{n}^{-1}\left(h_{n}\left(\varphi_{a}, \dot{\varphi}_{a}\right)+M_{n} \ddot{\varphi}_{a d}-M_{n} c e_{2}\right. \\
& \left.-\operatorname{sgn}\left(M_{n}\right) \widehat{\bar{\rho}}(t) \operatorname{sgn}(s)\right) \\
& =-s M_{n}^{-1} \operatorname{sgn}\left(M_{n}\right) \hat{\bar{\rho}}(t) \operatorname{sgn}(s)+s M_{n}^{-1} \rho(t)-\eta^{-1} \tilde{\boldsymbol{\omega}}^{T} \dot{\hat{\boldsymbol{\omega}}} \\
& =-\left|s M_{n}^{-1}\right| \boldsymbol{\omega} \wedge^{T} \boldsymbol{\sigma}\left(\varphi_{a}, \dot{\varphi}_{a}\right)+s M_{n}^{-1} \rho(t)-\eta^{-1} \tilde{\boldsymbol{\omega}}^{T} \dot{\hat{\boldsymbol{\omega}}} \\
& =-\left|s M_{n}^{-1}\right|\left(\boldsymbol{\omega} \wedge^{T} \boldsymbol{\sigma}\left(\varphi_{a}, \dot{\varphi}_{a}\right)+\bar{\rho}(t)-\bar{\rho}(t)\right) \\
& +s M_{n}^{-1} \rho(t)-\eta^{-1} \tilde{\boldsymbol{\omega}}^{T} \dot{\hat{\boldsymbol{\omega}}} \\
& \leq-\left|s M_{n}^{-1}\right|\left(\boldsymbol{\omega} \wedge^{T} \boldsymbol{\sigma}\left(\varphi_{a}, \dot{\varphi}_{a}\right)-\bar{\rho}(t)\right) \\
& -\left|s M_{n}^{-1}\right|(\bar{\rho}(t)-|\rho(t)|)-\eta^{-1} \tilde{\boldsymbol{\omega}}^{T} \dot{\widehat{\boldsymbol{\omega}}} \\
& =-\left|s M_{n}^{-1}\right|\left(\boldsymbol{\omega} \wedge^{T} \boldsymbol{\sigma}\left(\varphi_{a}, \dot{\varphi}_{a}\right)-\boldsymbol{\omega}^{* T} \boldsymbol{\sigma}\left(\varphi_{a}, \dot{\varphi}_{a}\right)\right. \\
& \left.+\varepsilon\left(\varphi_{a}, \dot{\varphi}_{a}\right)\right)-\left|s M_{n}^{-1}\right|(\bar{\rho}(t)-|\rho(t)|) \\
& -\left(\boldsymbol{\omega}^{* T}-\boldsymbol{\omega} \wedge^{T}\right)\left|s M_{n}^{-1}\right| \boldsymbol{\sigma}\left(\varphi_{a}, \dot{\varphi}_{a}\right) \\
& =-\left|s M_{n}^{-1}\right| \varepsilon\left(\varphi_{a}, \dot{\varphi}_{a}\right)-\left|s M_{n}^{-1}\right|(\bar{\rho}(t)- \\
& \leq\left|s M_{n}^{-1}\right|\left|\mathcal{E}\left(\varphi_{a}, \dot{\varphi}_{a}\right)\right|-\left|s M_{n}^{-1}\right|(\bar{\rho}(t)-|\rho(t)|) \\
& =\left|s M_{n}^{-1}\right|\left(\left|\varepsilon\left(\varphi_{a}, \dot{\varphi}_{a}\right)\right|-(\bar{\rho}(t)-|\rho(t)|)\right) \\
& \leq\left|s M_{n}^{-1}\right|\left(\varepsilon_{1}-\varepsilon_{0}\right) \leq 0 \text {. }
\end{aligned}
$$

If the model satisfies:

$$
\ddot{\varphi}_{a}=a_{1} \dot{\varphi}_{a}+a_{2} \varphi_{a}+b u+f_{d}
$$

The asymptotic stability of civil engineering structure control system can be guaranteed by using a deformed structure controller. The semiactive control model of civil engineering structure designed in this paper is bounded convergent [25].

\section{Analysis of Simulation Experiment}

In order to test the application performance of text method in semiactive control of civil engineering structure, the simulation experiment was carried out. ETABS software was used to simulate the specimen model of high-load civil engineering structure, and four groups of prefabricated structures with different thicknesses were designed. The compressive strength of civil engineering structure with ribbed floor is $12 \mathrm{MPa}$, the axial compressive strength is $25 \mathrm{MPa}$, and the elastic modulus of RCCb2 specimen is $2.45 \times 104 \mathrm{MPa}$. According to the above parameters, the mechanical distribution of civil engineering structure is obtained as shown in Figure 5.

According to the results of mechanical numerical analysis, semiactive control of civil engineering structure is carried out, and the load displacement of civil engineering structure is shown in Figure 5. The semiactive control convergence curve of civil engineering structures is shown in Figure 6. Figure 7 is the semiactive control convergence curve of civil engineering structures.

The simulation results show that the semiactive control of civil engineering structure with this method has good stability, and the strength and yield response strength of civil engineering structure are improved.

\section{Conclusions}

In this paper, a semiactive control model of civil engineering structure based on neural network is proposed, and the control constraint parameter model of semiactive regulation of civil engineering structure is constructed. Combined with the controlled object model, the semiactive control model of civil engineering structure is designed, the mechanical analysis model of civil engineering structure is established, 


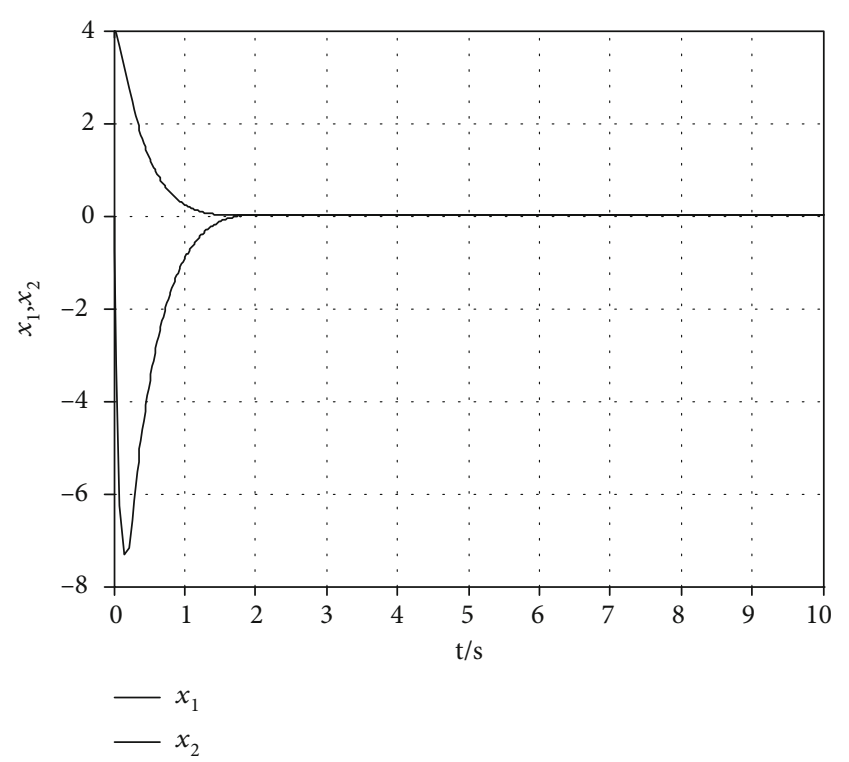

Figure 6: Load displacement of civil engineering structures.

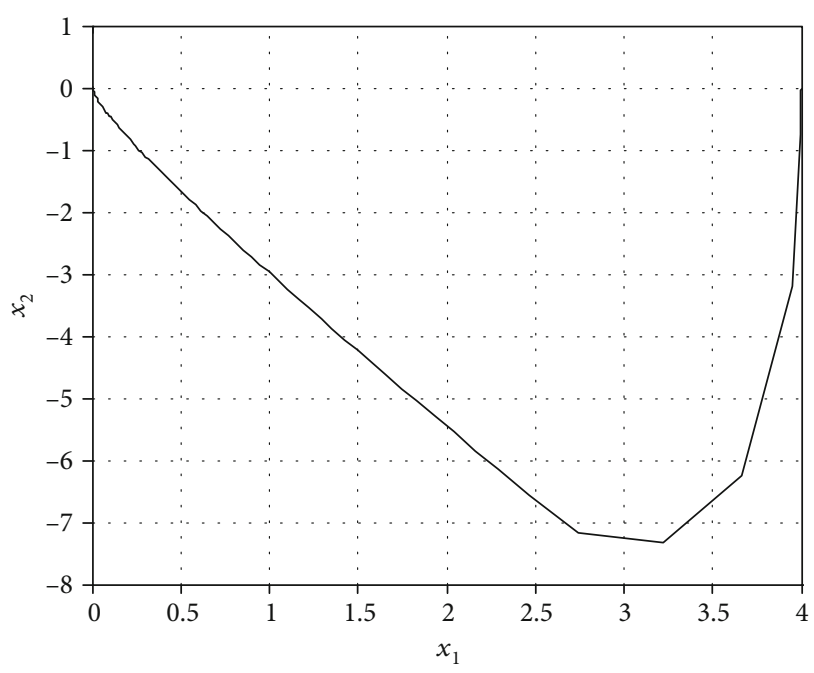

FIGURE 7: Semiactive control convergence curve of civil engineering structures.

and the semiactive regulation of civil engineering structure is carried out by the small disturbance suppression method. The semiactive adjustment of civil engineering structure is carried out by using the structural strength fusion tracking method. Taking the internal strength and shock yield response of civil engineering structure as constraint parameters, the semiactive control of civil engineering structure is carried out and PID neural network is used to optimize the control system. The simulation results show that the semiactive control of civil engineering structure with this method has good stability, the strength and yield response strength of civil engineering structure are improved, and it has good control efficiency. This method has good application value in the analysis and control of civil engineering structure mechanics.

\section{Data Availability}

The data in this paper are valid and available from the corresponding author.

\section{Conflicts of Interest}

This paper does not contain any conflict of interest.

\section{Acknowledgments}

The study is supported by the Major Science and Technology Projects of Sichuan Province, P. R. China (2018SZDZX0021).

\section{References}

[1] G. J. Parra-Montesinos, "High-performance fiber-reinforced cement composites: an alternative for seismic design of structures," ACI Structural Journal, vol. 102, no. 5, pp. 668675, 2005.

[2] A. Aviram, B. Stojadinovic, and G. J. Parra-Montesinos, "High-performance fiber-reinforced concrete bridge columns under bidirectional cyclic loading," ACI Structural Journal, vol. 111, no. 2, pp. 303-312, 2014.

[3] R. Ahmadi, O. Rashidian, R. Abbasnia, F. Mohajeri Nav, and N. Usefi, "Experimental and numerical evaluation of progressive collapse behavior in scaled RC beam-column subassemblage," Shock and Vibration, vol. 2016, Article ID 3748435, 17 pages, 2016.

[4] F. Dinu, I. Marginean, D. Dubina, and I. Petran, "Experimental testing and numerical analysis of 3D steel frame system under column loss," Engineering Structures, vol. 113, pp. 59-70, 2016.

[5] A. G. Vlassis, B. A. Izzuddin, A. Y. Elghazouli, and D. A. Nethercot, "Progressive collapse of multi-storey buildings due to sudden column loss-Part II: Application," Engineering Structure, vol. 30, no. 5, pp. 1424-1438, 2008.

[6] L. Lin, X. Lu, P. Han, S. Cen, and J. Liu, "Analysis of impact force of large commercial aircraft to a rigid wall," Journal of Vibration and Shock, vol. 34, no. 9, pp. 158-163, 2015.

[7] L.-H. Han, C.-C. Hou, X.-L. Zhao, and K. J. R. Rasmussen, "Behaviour of high-strength concrete filled steel tubes under transverse impact loading," Journal of Constructional Steel Research, vol. 92, pp. 25-39, 2014.

[8] R. Wang, L. H. Han, and C. C. Hou, "Behavior of concrete filled steel tubular (CFST) members under lateral impact: experiment and FEA model," Journal of Constructional Steel Research, vol. 80, no. 4, pp. 188-201, 2013.

[9] B. Xu and X. Zeng, "Experimental study on the behaviour of reinforced concrete beams under impact loadings," China Civil Engineering Journal, vol. 47, no. 2, pp. 41-51, 2014.

[10] D. Lü, X. Yu, and Z. Chen, "Lateral seismic collapse fragility analysis of RC frame structures," Journal of Harbin Institute of Technology, vol. 43, no. 6, pp. 1-5, 2011.

[11] X. Yu, D. Lü, and H. Zheng, "Seismic sideway collapse fragility analysis based on typical failure modes," Journal of Building Structures, vol. 35, no. 8, pp. 8-15, 2014.

[12] E. Taub, et al.G. Uswatte, M. H. Bowman et al., "Constraintinduced movement therapy combined with conventional neurorehabilitation techniques in chronic stroke patients with plegic hands: a case series," Archives of Physical Medicine and Rehabilitation, vol. 94, no. 1, pp. 86-94, 2013. 
[13] X. P. Zhou, X. F. Zhang, and X. N. Zhao, "Cloud storage performance evaluation research," Computer Science, vol. 41, no. 4, pp. 190-194, 2014.

[14] H. Liang, J. Zou, K. Zuo, and M. J. Khan, “An improved genetic algorithm optimization fuzzy controller applied to the wellhead back pressure control system," Mechanical Systems and Signal Processing, vol. 142, p. 106708, 2020.

[15] Y. Zhou, H. Zhang, F. Li, and P. Qi, "Local focus support vector machine algorithm," Journal of Computer Applications, vol. 38, no. 4, pp. 945-948, 2018.

[16] X. Xiong, L. Yang, Y. Ma, and Z. Zhuang, "Alerting algorithm of low-level wind shear based on fuzzy C-means," Journal of Computer Applications, vol. 38, no. 3, pp. 655-660, 2018.

[17] C. Lin, Y. X. He, and N. Xiong, "An energy-efficient dynamic power management in wireless sensor networks," in 2006 Fifth International Symposium on Parallel and Distributed Computing, pp. 148-154, Timisoara, Romania, 2006.

[18] Y. Yang, N. Xiong, N. Y. Chong, and X. Défago, "A decentralized and adaptive flocking algorithm for autonomous mobile robots," in 2008 The 3rd International Conference on Grid and Pervasive Computing - Workshops, pp. 262-268, Kunming, China, 2008.

[19] Y. Liu, M. Ma, X. Liu, N. N. Xiong, A. Liu, and Y. Zhu, "Design and analysis of probing route to defense sink-hole attacks for Internet of Things security," IEEE Transactions on Network Science and Engineering, vol. 7, no. 1, pp. 356-372, 2020.

[20] H. Liang, J. Zou, Z. Li, M. J. Khan, and Y. Lu, "Dynamic evaluation of drilling leakage risk based on fuzzy theory and PSO-SVR algorithm," Future Generation Computer Systems, vol. 95, pp. 454-466, 2019.

[21] C. Lin, N. Xiong, J. H. Park, and T. Kim, "Dynamic power management in new architecture of wireless sensor networks," International Journal of Communication Systems, vol. 22, no. 6, pp. 671-693, 2009.

[22] Y. Sang, H. Shen, Y. Tan, and N. Xiong, "Efficient protocols for privacy preserving matching against distributed datasets," in Information and Communications Security. ICICS 2006, vol. 4307 of Lecture Notes in Computer Science, pp. 210227, 2006.

[23] F. Long, N. Xiong, A. V. Vasilakos, L. T. Yang, and F. Sun, “A sustainable heuristic QoS routing algorithm for pervasive multi-layered satellite wireless networks," Wireless Networks, vol. 16, no. 6, pp. 1657-1673, 2010.

[24] J. Li, N. Xiong, J. H. Park, C. Liu, S. MA, and S. E. Cho, "Intelligent model design of cluster supply chain with horizontal cooperation," Journal of Intelligent Manufacturing, vol. 23, no. 4, pp. 917-931, 2012.

[25] W. Guo, N. Xiong, A. V. Vasilakos, G. Chen, and C. Yu, "Distributed k-connected fault-tolerant topology control algorithms with PSO in future autonomic sensor systems," International Journal of Sensor Networks, vol. 12, no. 1, pp. 53-62, 2012. 